Годишьак Филозофског факултета у Новом Саду, Кюига ХХХІХ-2 (2014)

Annual Review of the Faculty of Philosophy, Novi Sad, Volume XXXIX-2 (2014)

Bojana Vujin

Filozofski fakultet Univerziteta u Novom Sadu

UDK 81'42:78.011.26

Originalan naučni rad

\title{
„BESMISLENE LJUBAVNE PESMICE“: KAKO PRISTUPITI POP I ROK POEZIJI? ${ }^{1}$
}

Priroda popularne muzike je takva da se njen tekstualni deo često zanemaruje u odnosu na njenu muzičku komponentu. Cilj ovog rada jeste da utvrdi da li je to zaista opravdano. Polazeći od veze između tradicionalne, umetničke poezije i njenog popularnog, pop i rok oblika, te istražujući sve one elemente (kao što su grafički izgled pesme, stilske figure dikcije, rima, metrika) koji doprinose boljem razumevanju poezije uopšte,može se zaključiti da ove dve poetske vrste imaju više sličnosti nego razlika. Iz ovoga sledi da se i pop tekst može analizirati na isti način kao i umetnička poezija, kroz pristupe kakav su hermeneutički ili intertekstualni.

Ključne reči: poezija, popularna muzika, hermeneutika, intertekstualnost, tekst pesama

U filmu Muzika i tekst (Music and Lyrics, 2007), Aleks Flečer (Hugh Grant), ocvali muzičar koji je osamdesetih godina bio zvezda danas zaboravljenog benda Pop! (parodije na stvarni bend Wham!), traži tekstopisca čiji će mu stihovi pomoći u pokušaju da dosegne nekadašnje muzičke visine. Razgovarajući sa Sofi Fišer (Drew Barrymore), kućnom pomoćnicom na zameni koja će holivudskom igrom slučaja popuniti upražnjeno stvaralačko mesto, kaže joj da samo nešto nažvrlja pošto je to samo tekst, a tekst nije važan kao melodija. Ona mu na to odgovara da je melodija prvi susret s nekim, fizička privlačnost, seks, dok je tekst upoznavanje osobe, onakve kakva je zaista, ispod svega, i zaključuje da magiju stvara kombinacija ta dva aspekta. U ovakvo ustrojstvo u popularnoj muzici ne veruju samo izmišljeni likovi iz romatičnih komedija - kognitivni muzikolog Danijel Levitin (Daniel Levitin) navodi da Sting u uvodu u zbirku svojih tekstova kaže da muzika i tekst idu zajedno, a njihovu međusobnu zavisnost ilustruje koristeći se analogijom lutke u izlogu i odeće na njoj - jedna bez druge nemaju smisla; ako se razdvoje, ostaju samo gola plastična lutka i bezoblična hrpa tekstila (cit. u: Levitin, 2010, 23).

A opet, mišljenje Aleksa Flečera delili su - a i dalje dele - mnogi predstavnici muzičke industrije, te teoretičari muzike i popularne kulture, pa čak i umetnici. Dante tako smatra da rajski skladan zvuk, ,ima toliko ubedljivu snagu da razumljivost teksta praćenog muzikom postaje nevažna“"(Dona, 2008, 62). Leonardo da Vinči veruje u ,primat muzike nad poezijom“(Dona, 2008, 64), dok Šenberg tvrdi

\footnotetext{
bojvuj@gmail.com
} 
da „muzika ne treba da 'služi' tekstu“ (Dona, 2008, 125). Kada je reč o muzičkoj industriji, dovoljno je setiti se sledeće epizode. Godine 1918, u odgovoru na pismo Redklif Hol (Radclyffe Hall) koja se požalila što nije dobila autorski honorar za tekst izuzetno uspešne pesme "The Blind Ploughman“, Vilijam Dejvi (William Davey), predsednik muzičke kompanije koja je objavila pesmu, napisao je da su „mnogi tekstovi samo ponavljanje istih reči različitim redosledom, a gotovo uvek sa istim idejama. Iskreno, skoro nijedan ne zavređuje honorar, premda se s vremena na vreme može desiti i suprotno. Teško je, međutim, to odrediti" ${ }^{\text {“2 }}$ (cit. u: Frith, 1988, 105).

Isto tako, bez obzira na to što je pedesetih i šezdesetih godina prošlog veka popularna muzika ušla u akademske krugove upravo preko teksta (Frith, 1988, 105), nedugo potom, analiza reči pesama poklekla je pred sociološki i kulturološki obojenim pristupom, a sama ideja da tekst uopšte i ima neko značenje potpuno je marginalizovana (Moore, 2003, 11). Tim Vol (Tim Wall) tvrdi da je, na samom početku, najzastupljeniji pristup izučavanju popularne muzike bio analiza teksta, te da

rane studije koje su sproveli Džon Pitman (John Peatman, 1944) i H. Muni (H. Mooney, 1954; 1968) pretpostavljaju da je tekst najznačajniji deo pesme, i da se psihološka stanja slušalaca, pa čak i čitavih društava mogu odrediti kategorizacijom tekstova pesama koje slušaju (Wall, 2003,128).

Roj Šuker (Roy Shuker) pak kaže da je tekst dominirao ranom kritikom popularne muzike samo zato što je takav pristup imao osnova u već poznatoj istraživačkoj metodologiji - analizi sadržaja (Shuker, 2001, 141). Sa ovim se, izgleda, slaže i Lars Ekštajn (Lars Eckstein), pitajući se zbog čega tekst, ako je toliko važan, stalno izmiče „mrežama akademskog ribarenja“, i zaključuje da

[b]ez sumnje, većina tekstova na papiru deluje banalno i ne dostiže standard prihvaćene književne analize i estetskog suda. Takva tumačenja, međutim, previđaju da ono što je zanemarljivo kao pesma može na složen način funkcionisati na preseku zvučnog, društvenog, telesnog i medicinskog diskursa (Eckstein, 2010, 14).

Šta god da je razlog - dolazak nekog drugog, primamljivijeg kritičkog pristupa ili pak činjenica da je već i pre početka književne analize muzički tekst stavljen u nezahvalan položaj, jer mu se pristupa isto kao i književnom tekstu naspram kogaprečesto deluje manjkavo - tek, primat tekstualnog nad muzičkim i kulturološkim sadržajem nedugo potom pao je u zaborav.

Naravno, i kritičko-teorijski snobizam prema kome sve što je popularno automatski jeste i loše odigrao je u svemu ovome određenu ulogu. Tako, na primer, Teodor Adorno (Theodor Adorno) popularnu muziku, koju suprotstavlja ,pravoj“, „ozbiljnoj“ muzici, kritikuje zbog njene standardizovanosti i manipulativnosti (vid. Adorno, 1941 u: Frith \& Goodwin, 1990, 256-267), kao i zbog toga što

Svi citati u radu dati su u vlastitom prevodu, osim ako je u bibliografiji drugačije naznačeno. 
predstavlja uzdanicu omražene mu masovne kulture. (Današnjim generacijama ne promiče ironija činjenice da Adorno, koji svoj rad o popularnoj muzici piše na samom početku četrdesetih godina dvadesetog veka, pod tom standardizovanom, veštačkom muzikom podrazumeva džez - koji je za nekog Adorna iz dvadeset prvog veka možda sinonim za „ozbiljnu“ i „pravu“ muziku koja opstaje uprkos petparačkim trendovima.) Prve analize popularnih muzičkih tekstova (vid. na primer tekst Donalda Hortona u: Frith \& Goodwin, 1990, 11-21) slede ove ideje i tekstove popularnih pesama grupišu u tek nekoliko, međusobno veoma sličnih i veoma predvidivih tematskih celina (Horton, recimo, u svome radu piše o čeznutljivim ljubavnim pesmama namenjenim adolescentima - što, istini za volju, 1957. godine, kada je tekst napisan, verovatno i jeste bilo nešto najzastupljenije u popularnoj muzici, mada bi se mogao dati i argument u prilog tvrdnji da su takve pesme uvek najpopularnije, bez obzira na doba, jer je omladina primarna publika popularne muzike, nevezano za žanr). U svakom slučaju, nakon što je, s pojavom kako ozbiljnijih popularnih bendova, tako i širih studija kulture, akademsko istraživanje popularne muzike steklo određeni renome, retko kad je izlazilo iz okrilja već pomenutih socioloških studija. Alan Mur (Allan Moore) kaže da su reči pesama strana teritorija za muzikologe, koji se bore da svoje kolege nateraju da pop muziku uopšte i shvate ozbiljno, ali da je najinteresantniji ipak krajnji nemar književnih kritičara, za koje je „,poezija“ ružna reč cele oblasti studija popularne muzike (Moore, 2003, 40-41). A Sajmon Frit (Simon Frith) i Endru Gudvin (Andrew Goodwin), u uvodu u zbirku eseja o roku i popu koju su priredili 1990. godine (On Record: Rock, Pop, and the Written Word), napominju da

akademske studije pop i rok muzike imaju osnovu u sociologiji, ne muzikologiji (koja, čak i danas, pokazuje u najboljem slučaju tek marginalno interesovanje za popularnu muziku), a sociologija popa i roka, sa svoje strane, ima osnovu u dve nemuzičke ideje: značenju „masovne kulture“ $i$ empirijskom istraživanju omladine (i delinkvencije) (Frith \& Goodwin, 1990, 1).

S druge strane, Fabijan Holt (Fabian Holt) kaže da je polje studija popularne muzike prilično neorganizovano, te da se razvilo ,iz vrlo različitih tradicija kao što su britanske studije kulture, nemačka muzikologija, istočnoazijske medijske studije i američke studije folklora, što delimično objašnjava odsustvo neke zajedničke metodologije“ (Holt, 2007, 1).

Kako onda pristupiti istraživanju popularne muzike i muzičkog teksta? Ne samo da je reč o oblasti koja, kao i, na primer, dečija književnost, stoji na granici između nekoliko disciplina - muzikologije, nauke o književnosti, neurologije, sociologije, kulturologije - već (opet, poput dečije književnosti) zauzima prostor između umetničkog i popularnog, što bi možda bio još jedan dokaz u prilog činjenici da ta dva pojma nipošto ne bi trebalo (olako) razdvajati, o čemu govori i Teodor Grejsik (Theodore Gracyk) u uvodu svojoj knjizi o estetskoj vrednosti popularne muzike (Gracyk, 2007, 2). Kada je o metodološkom pristupu reč, Ričard Midlton (Richard Middleton) kaže da ,dominatna tema kod mlađe generacije pop 
muzikologa koji su se pojavili od sedamdesetih godina do danas, i na koje su uticale novonastale kulturne studije, jeste upravo pitanje analitičkog metoda: kako pristupiti pop tekstu?" (Middleton, 2001, 217)

Uprkos decenijama izučavanja koje su iznedrile originalne i pronicljive radove, studije popularne muzike i dalje nemaju kredibilitet kakav, recimo, s pravom pripada filmskoj kritici (vid. uvod Entonija Dekertisa (Anthony DeCurtis) u Dettmar \&Richey, 1999). Možda se razlog za ovo krije u tome što film kao umetnost nema svoj visokoparni ekvivalent - on jeste proistekao iz pozorišta, ali ta dva oblika umetnosti dovoljno su različiti i odvojeni jedan od drugog da se filmu u njihovom odnosu ne dodeljuje uloga neozbiljnog mlađeg brata. Popularna muzika nije te sreće - uvek iza nekog ugla vreba kakav adornista koji žuri da pokaže kako je popularna muzika nezreli adolescent, nedostojan članstva u porodici sa „ozbiljnom“, „klasičnom“, „,umetničkom“ muzikom. Naravno, još jedna ironija može se pronaći u činjenici da je današnja „ozbiljna“ muzika ništa drugo do popularni hit jučerašnjice - Mocart i Šopen su nekada smatrani laganom, zabavljačkom muzikom u odnosu na „umetničkiji“ izraz Baha i Betovena, na primer, dok su valceri i polke, koji se danas u potpunom miru i tišini slušaju u koncertnim dvoranama, u minulim vekovima bili plesna muzika koja se svirala na zabavama. A ne sme se zaboraviti ni to da je možda i prvi superstar u današnjem smislu te reči bio niko drugi do čuveni tenor Enriko Karuzo (Enrico Caruso), čija je izvedba arije "Vesti la Giubba" iz Leonkavalove opere Pajaci bila prva ploča prodata u više od milion primeraka, početkom dvadesetog veka, te da hitovi pop-opere koje su u drugoj polovini dvadesetog veka uveli Endru Lojd Veber (Andrew Lloyd Webber) i Tim Rajs (Tim Rice), te Fredi Merkjuri (Freddie Mercury) i Monserat Kabalje (Montserrat Caballé), a nastavili najpre Tri tenora, a potom i skandinavski simfonijski metal bendovi, nikako nisu potpuna inovacija, već samo rekontekstualizacija nekadašnje muzičke mode. Sve ovo svedoči u prilog ideji da kulturni kontekst i kritički trend umnogome određuju status neke umetnosti ili discipline koja se njome bavi, te da toj sudbini nije mogla umaći ni popularna muzika; to, međutim, nipošto ne znači da joj se može osporiti estetska ili umetnička vrednost, bez obzira na stavove koji u nekom trenutku dominiraju u kritici.

Ovo je naročito prikladno ako se imaju u vidu postmodernističke ideje koje se u najvećem broju slučajeva direktno suprotstavljaju modernističkom antagonizmu prema masovnoj kulturi (vid. McRobbie 1995, 14). Andžela Makrobi (Angela McRobbie) navodi da je,,postmodernizam ušao u raznovrsniji broj diskursa mnogo brže nego većina drugih intelektualnih kategorija. Proširio se iz okrilja istorije umetnosti na političku teoriju i na stranice časopisa omladinske kulture, omote muzičkih albuma i modne oglase u Vougu“ (McRobbie, 1995, 15). Isto tako, postmodernistički kontekst nudi ,šire i dinamičnije razumevanje predstava sadašnjosti nego bilo koji raniji pristup“ (McRobbie, 1995, 13). Postmodernizam, dakle, omogućava podjednak status tradicionalnoj i popularnoj umetnosti, te onim izrazima koje dominantne kritičko-teorijske ideje od pre svega nekoliko decenija možda uopšte ne bi ni smatrale umetnošću. No, i ovo je mač sa dve oštrice, jer 
ako je sve jednako dostojno istraživanja, onda je teško odrediti šta je zaista umetnički vredno, a šta prosto, zbog svoje površne prirode, zgodno kao subjekt teorijskog razmatranja, bez obzira na to što površnost ne mora nužno da označava nešto loše, već može biti namerna, subverzivna politička strategija (vid. McRobbie, 1995, 4). Šta ovo znači za tekst popularnih pesama? Ingvar Stajnholt (Yngvar Steinholt) kaže da je tvdnja da su reči deo značenja pesme postala nedovoljna tokom postmodernog talasa rok studija kasnih osamdesetih i ranih devedesetih godina dvadesetog veka, te da je dominantno viđenje bilo ono po kome reči pesama ne moraju, pa čak ni ne treba, da znače apsolutno ništa. On dalje navodi da je „svaka književna (ili muzička) analiza pop pesma postala nebitna, passé i vredna ne više od usputnog podrugljivog osmeha prosvetljenog postmoderniste“" (Steinholt, s.a., 1).

Sve je ovo, ipak, kao što je već napomenuto, samo odraz kritičkih trendovareči popularnih pesama prešle su ,dug i zavojit put“ na čijem su početku bile najznačajniji, analize vredan, deo pesme, potom su postale podređene ne samo njenom muzičkom, već i društveno-kulturnom kontekstu, da bi na kraju postale potpuno nebitne i nevažne, tek postscriptum svim ostalim elementima što čine jednu popularnu pesmu, koja ni sama ne zavređuje tek neznatnu pažnju. A opet, top-listama ne dominiraju instrumentali, autori se trude da budu ne samo dobri kompozitori, muzičari i izvođači, već i tekstopisci, a publika nastoji da zapamti reči i na koncertima peva zajedno sa bendovima. Tekstovi pesama očigledno u skorije vreme neće nestati, što je samo po sebi dovoljan razlog da im se ne odriče značaj, već da im se posveti dužna kritička pažnja.

No, ta kritička pažnja ipak ne uspeva dovoljno dugo da ostane usmerena na tekstualni aspekt pesme. „Zašto pesme imaju reči“ ("Why do songs have words?"), na primer, bukvalni je naslov rada Sajmona Frita o tekstovima popularne muzike. Pišući iz ugla kulturologa popularne muzike koji čak priznaje da je, po njegovom mišljenju, tekst najnebitniji deo pesme koji je stoga namerno zanemario u Sociologiji roka (The Sociology of Rock, 1978), on pesme naziva "oblikom propagande“ (Frith, 1988, 110) i objašnjava zbog čega su reči pesama bile bitne američkim sociolozima (navodi, na primer, razliku u ljubavnim odnosima pedesetih i šezdesetih godina dvadesetog veka, koja se može uočiti analizom tekstova pesama - vid. Frith, 1988, 107). Dok piše o razlici između roka i popa, Frit navodi da

pravi rok tekstovi značajni su zato što se mogu posmatrati kao poezija ili politika, uključuju nekakav društveni komentar ili istinitost osećanja; loši rok tekstovi su čista koještarija. /.../ Mejnstrim, komercijalni pop tekstovi - besmislene ljubavne pesmice - možda nemaju ,značaj“ za svoju publiku kao što ga imaju rok tekstovi, ali nisu stoga i beznačajni. Popularna muzika je vrsta pesme; reči su razlog zbog koga ljudi kupuju ploče; instrumentalni hitovi su i dalje neuobičajeni (Frith, 1988, 120).

Ako se zanemari prilično snobovska podela na ,autentični“ rok i „komercijalni“" pop, ono što se izdvaja kao značajno iz Fritovog teksta jeste upravo to što čak ni najubeđeniji kulturolozi i sociolozi ne mogu da ospore da tekstovi pesama, ma 
kako beznačajni i besmisleni izgledali na prvi pogled, imaju i te kako važnu ulogu u celokupnom značenju pesme. Takođe, može se uočiti i trend po kome tekst popularne pesme dobija na značaju ako je po svojoj tematici politički - što, naravno, nije istinito, i insistiranje na tome bilo bi podjednako apsurdno kao i negiranje vrednosti bilo koje umetnosti osim angažovane (pogotovo zato što je angažovana umetnost tek u retkim slučajevima iskrena). Ma kako kratkovido takvo posmatranje bilo, ono je ipak dominantno, i jasno pokazuje da, čak i kad se tekstu pesme ne osporava značaj, on se opet najčešće analizira kao kulturološki, a ne književni fenomen. To, naravno, ne znači da je književna analiza nemoguća ili besmislena, već samo da je neuobičajena. Prvi korak u toj analizi bilo bi utvrđivanje koliko poezije zapravo ima u poeziji popularne kulture, tj. u tekstovima popularnih pesama.

Engleski termini za popularne pesme koje se pevaju i umetničke ili narodne pesme koje su deo književnosti potpuno su različiti - u prvom slučaju govorimo o obliku koji se zove song, u drugom o poem. To bi već samo po sebi trebalo da nam ukaže na činjenicu da su u pitanju dve potpuno različite umetničke vrste. A opet, postoje pesnici - poput Vilijama Blejka (William Blake) ili Džona Berimana (John Berryman) - koji svoju poeziju namerno nazivaju ne umetničkim, već pevačkim pesmama (Blejkova najpoznatija zbirka zove se - skraćeno - Songs of Innocence and Experience, Berimanova Dream Songs). Ako se ovome doda i to da engleski termin za tekst popularnih pesama, lyrics, ima koren u reči lyre, lira, te da je lirska poezija prvobitno i bila izvođena uz pratnju tog instrumenta, očito je da ova podela na umetničku i pevanu poeziju i nije tako kruta, kao i da su granice između ta dva oblika možda mnogo manje jasno definisane nego što nam se na prvi pogled čini. Tu su, zatim, i pesnici poput jednog od pripadnika Čikaške škole poezije, Vejčela Lindzija (Vachel Lindsay), koji je svoje pesme izvodio uz pratnju bendža, ili Alena Ginzberga (Allen Ginsberg), koji jeod poezije pravio performans, i ne samo što je svoje pesme često pevao uz muzičku pratnju (dovoljno je pogledati bilo koji snimak njegovog izvođenja pesme "Father Death Blues" na jutjubu), već je snimao i albume i nastupao sa bendovima kao što je Kleš (The Clash). Očigledno, umetnička poezija ne boravi sve vreme u kuli od slonovače, a antički pesnici i srednjovekovni trubaduri nisu jedini koji su je odatle iznosili na ulice. Štaviše, kako navodi Lars Ekštajn, potpuna podela na pisanu i izvodivu poeziju relativno je skori fenomen - počela je da se uvodi u prvoj polovini šesnaestog veka, kada je Vajat (Wyatt) u englesku književnost uveo Petrarkine sonete, nakon čega je jampski pentametar počeo postepeno da preuzima primat u engleskoj poeziji, zamenivši dotada češći i ,pevljiviji“ tetrametar (Eckstein, 2010, 12). Osim toga, ne smeju se zaboraviti ni trendovi: nekada su pesnici uživali mnogo veću slavu nego danas, a čitanja poezije bila su masovni, zajednički doživljaj. Romantičarski pesnici, na primer, bili su podjednako slavni kao i današnji muzičari, i vrlo je verovatno da bi, da su danas živi, ondašnji pesnički idoli poput lorda Bajrona (Lord Byron) pre bili rok zvezde nego pesnici. Ako se ima u vidu i obrnuto, da se neke od današnjih muzičkih zvezda, poput Boba Dilana (Bob Dylan) 
ili Lenarda Koena (Leonard Cohen), pre mogu nazvati pesnicima koji svoju poeziju izvode nego pevačima čiji tekstovi imaju karakteristike umetničkih pesama, jasno je da u poeziji popularne kulture, odnosno u tekstovima popularne muzike, i te kako ima „prave“" poezije.

Kritičari se, naravno, ne slažu oko toga. Tako, na primer, Danijel Levitin spominje razgovor koji je nekom prilikom vodio sa svojim nekadašnjim profesorom poezije, koji mu je rekao da muzički tekstovi svakako jesu poezija, i da, premda je reč o posebnoj vrsti poezije, između muzičkog teksta i umetničke pesme ne postoji potpuna razlika, što ilustruje već navedenim argumentom: da lirska poezija s pevanjem, poput elizabetinske ili srednjovekovne trubadurske poezije, postoji oduvek i s vremenom samo menja oblik (Levitin, 2010, 24). Lars Ekštajn, s druge strane, tvrdi da „muzički tekstovi nisu poezija, i njihovo proučavanje stoga zahteva drugačiji analitički aparat nego što je onaj koji se tradicionalno primenjuje na poeziju“ (Eckstein, 2010, 23). Stiven Lubke (Steven Luebke), opet, kaže da ,[p]opularna muzika u izučavanju književnosti nije zamena za tradicionalne tekstove, već pre njihova dopuna. Istu tekstualnu analizu koja se na časovima književnosti obavlja na kanonskim tekstovima možemo primeniti i na mnoge tekstove popularnih pesama" (Luebke, 1995, 11).

Razliku između „ozbiljne“ poezije (serious poetry) i stihova (verse) naglašava i Džon Bar (John Barr), koji u stihove, pored tekstova popularne muzike (u njegovom slučaju, repa i hip-hopa), svrstava i dečije pesme (čak i lingvistička remek-dela kao što je Kerolov „Džabervoki“, na primer), i svoj esej zaključuje tako što priznaje da stihovi imaju neki značaj, mada ih smatra manje umetnički vrednim od ,prave“" poezije (vid. Barr, 2006). Alan Mur pak naglašava da nisu toliko bitne razlike između pop pesama i poezije, već slučajevi gde se te razlike zamagljuju, navodeći kao primer činjenicu da se od doba Bitlsa (The Beatles) reči pesama često štampaju na omotima albuma, a da neki tekstopisci svoje stihove objavljuju u formi knjige i kao rešenje nudi sledeće zapažanje:

Ono što treba da se desi, bar se meni tako čini, jeste da, najpre, i najvažnije, prestanemo da mislimo da reči pop pesama jesu poezija, te da počnemo da govorimo da su one poput poezije, u određenom smislu; isto tako, ako nisu poput poezije, onda možda naginju ka tome da budu poput proze (Moore, 2003, 42).

Očigledno je da su mišljenja o ovoj temi podeljena, no, ako treba obaviti književnu analizu tekstova popularnih pesama, najlogičnije je te tekstove smatrati poezijom, ili makar oblikom poezije, s obzirom na to da sâm metodološki pristup podrazumeva da se isti kritički aparat rezervisan za ono što se bezrezervno smatra poezijom primenjuje i na pop tekst. U čemu se, dakle, kriju sličnosti i razlike između pop poezije i njenog tradicionalnijeg, umetničkog ekvivalenta?

Najpre, kako navodi Lars Ekštajn, i jedan i drugi oblik umetnosti

koriste verbalni jezik, često uz karakteristična retorička i stilska sredstva, da ispriča priču (u baladnoj tradiciji), da iskaže ideje o životu i svetu, ponekad da ilustruje 
ograničenja s kojima se jezik susreće u odnosu „subjekta“" sa „svetom“. A opet, razlikuju se u makar jednom aspektu: dok se glas u poeziji generalno razume kao internalizovan, kodiran u medijumu pisanja, glas pop teksta je po definiciji eksterni. To znači da se tekstovi ne mogu pojmiti izvan konteksta njihovog glasovnog (i muzičkog) ostvarenja, to jest, njihove izvedbe (Eckstein, 2010, 10).

Ono o čemu Ekštajn govori jeste zapravo nešto sasvim očigledno: u pisanoj, umetničkoj poeziji, pisana reč je sve; zlobnici bi možda rekli „mrtvo slovo na papiru“ čije je celokupno postojanje sadržano upravo u pisanom medijumu; kada je reč o popularnim pesmama, njihov verbalni deo, tekst, samo je jedan od elemenata i sam po sebi nije dovoljan - kao što je muzika bez teksta nepotpuna, tako ni tekst bez muzike ne može da opstane, s obzirom na to da ona u velikoj meri određuje kako će taj tekst izgledati - od dužine stiha, preko ritma, potom izbora reči - zbog rime i načina na koji ona funkcioniše unutar pesme, pa sve do izgovora pojedinih reči - njihove dužine ili akcenta, u zavisnosti od potrebe muzičke fraze i idiosinkrazija u glasu i načinu izvođenja samoga pevača. Ekštajn navodi da ,prelaz sa poezije na tekst pesme“ dodaje makar „dva glasa“: ,glas „muzike“ u najširem smislu i stvarni, „otelotvoreni“"glas izvođača“ (Eckstein, 2010, 43).

A ipak, često se govori o „muzičkom aspektu“ poezije. Ritam, stopa, rima, izbor reči; potom stilske figure poput aliteracije, asonance, onomatopeje, anafore ili epifore; raspored stihova i strofa - sve ovo daje određeni zvuk pesmi, a zvuk je, kako Filip Pulman (Philip Pullman) kaže u uvodu u Miltonov Izgubljeni raj, nesumnjivo deo značenja i nipošto se ne sme zanemariti u celokupnom tumačenju nekog pesničkog dela; štaviše, ponekad je možda i važnije osetiti kao pesma zvuči nego razumeti šta ona znači. Tu su, osim toga, i književna dela koja namerno pozajmljuju neke muzičke forme i manje ih ili više uspešno prilagođavaju pisanom medijumu - jedno od poglavlja u Džojsovom Uliksu koristi formu fuge, dok je na stvaranje i oblik, pa čak i naslov Eliotova Četiri kvarteta uticala Betovenova muzika. Ipak, poezija mora da pribegava stilskim sredstvima, aluzijama, te formalnom oponašanju ne bi li publici predstavila i/ili približila onaj muzički element koji pop pesma poseduje u daleko većoj meri, a koji se ni ne nalazi u tekstu, već izvan njega, u muzici. Tako, na primer, čitajući Blejkovog „Tigra“, mi, zahvaljujući pesnikovom izboru reči i zvukova, možemo, „čuti“ udarce čekića i škripu lanaca koji prate stvaranje tigra; ali ta je muzika ipak u najvećoj meri metaforična i internalizovana, u potpunosti zavisna od čitaočevog glasa. Poezija muziku mora da dočara, dok je u popularnim pesmama ona bukvalna.Kako kažu Kevin Detmar (Kevin Dettmar) i Vilijam Riči (William Richey),

iako pesnik može upućivati na neku Bahovu sonatu ili Betovenov gudački kvartet, on se na te umetničke forme može pozvati samo kroz nemi medijum pisanja. Nasuprot tome, Džordž Martin je mogao da unajmi stvarni kvartet za „Elenor Rigbi“, čime je $\mathrm{u}$ isto vreme pretvorio Makartnijevu jednostavnu pop melodiju u nešto poput evropske umetničke pesme i nagovestio izvesnu ozbiljnost namere i dubinu značenja koje sam tekst ne bi mogao da iznese (Dettmar \&Richey, 1999, 3). 
Danijel Levitin, pišući o istoj temi, dolazi do zaključka da tekstovi pop pesama,,uvek imaju muziku koja će im pomoći, melodije i harmonije koje mogu da obezbede /.../ neki harmonijsko-tekstualni kontekst. Drugim rečima, tekst nije koncipiran tako da stoji sam [bez muzike]“ (Levitin, 2010, 25).

Dakle, kada je reč o muzičkom sadržaju, tekst poezije je, paradoksalno, obično bogatiji zvučnim stilskim sredstvima, iz prostog razloga što se ne može osloniti na neku stvarnu muziku koja će taj zvuk preneti. Tekst pop pesama može, ali ne mora da dočarava i zvuk, jer je muzički element pesme tu da nadoknadi - i to mnogo bolje nego što bi pesnička sredstva mogla - melodiju. Još jedna zanimljiva razlika između ova dva oblika pesništva ogleda se u sledećem: poezija ima ono što većina muzičkih tekstova nema (pogotovo u današnje doba, kada najveći broj kupljenih pesama dolazi u obliku kompjuterskih fajlova, a ne fizičkih objekata koji imaju omot i na njemu odštampane reči pesama), a to je grafički element. Od sonetskih varijacija u renesansnom dobu i podele standardnih četrnaest stihova na dva katrena i dva terceta ili tri katrena i jedan distih, preko viktorijanske poezije nonsensa (Kerolova Alisa u zemlji čuda, na primer, sadrži pesmu o mišu koja, rasporedom i dužinom stiha, te postepenim smanjivanjem veličine slova, postiže uvijeni izgled koji podseća na mišji rep), pa do pesnika poput e. e. kamingsa (e. e. cummings) čije se pesme tumače ne samo na osnovu onoga što u njima piše, već i načina na koji to piše - od vizuelnog prostora koji zauzimaju na papiru, do interpunkcije i specifičnog pravopisa koji se proširuje i na samo pesnikovo ime - grafički prikaz pesme, način na koji su reči vizuelno raspoređene, i te kako utiče na njihovo čitanje i razumevanje. Pop pesme, opet, veoma često dolaze uz pratnju video-spotova, koji im daju još jedan nivo značenja i/ili tumačenja, a koji ne postoji u pisanoj poeziji (mada, naravno, i tu ima izuzetaka - opet bi kao primer mogao poslužiti Ginzberg, ovoga puta njegova pesma „Balada kostura“ za koju je, u saradnji s Polom Makartnijem (Paul McCartney), načinio i spot).

Dalje, ni poezija ni pop muzika obično ne nastaju tako što autori stvaraju jedno po jedno delo, a da pritom nemaju baš nikakvu ideju o tome kako će ta individualna dela funkcionisati unutar neke veće celine - pesničke zbirke, odnosno, muzičkog albuma. I to ukazuje na određene sličnosti između ova dva oblika umetnosti. Kao što ton i ideja nekog muzičkog albuma zavise od redosleda pesama, tako $i$ raspored pesama u zbirci diktira njeno razumevanje - dovoljno je setiti se knjige Arijel (Ariel, 1965), posthumne zbirke pesama Silvije Plat (Sylvia Plath) i skandala koji je nastao zato što je Ted Hjuz (Ted Hughes) izmenio raspored pesama kada je priređivao zbirku za štampu: kada je, godinama kasnije, izašla originalna verzija zbirke, s pesmama po redosledu koji im je sama pesnikinja namenila, postalo je očigledno koliko se tumačenje cele knjige razlikuje u zavisnosti od rasporeda pesama - u jednom slučaju, naglasak je na mentalnoj propasti već odavno izgubljene osobe čija je patnja u najvećoj meri samoindukovana; u drugom, na kliničkoj depresiji izazvanoj ne samo unutrašnjim, već i spoljnim faktorima, poput muževljevog neverstva i propalog. A dovoljno je setiti se i bilo kog konceptualnog albuma (na pamet pada The Wall grupe Pink Flojd), pa shvatiti da bi izmena redosleda pesama na njemu dovela i do različitog tona, te samim tim i različitog razumevanja. 
Iz svega ovoga može se zaključiti da, ma koliko pisana i izvodiva poezija bile različite, one su ipak dovoljno slične da se mogu tumačiti na sličan način. Možda bi se veza između ova dva oblika najbolje mogla objasniti analogijom sa evolucijom - niti je poezija nastala od muzičkog teksta, niti tekst od poezije; pre bi se moglo reći da imaju zajedničkog pretka, i da je u nekom trenutku svaki od ovih oblika krenuo svojim putem; ipak, i dalje su zadržali mnoge zajedničke karakteristike i jedan su drugome najbliži srodnici.

S druge strane, može se dati i argument u prilog ideji da književni rod koji je najsličniji pop pesmama nije poezija, već drama. Sajmon Frit kaže da je pesma uvek izvedba, da se njene reči uvek čuju kao nešto izgovoreno, pogotovo zato što „[p]evači koriste i neverbalna i verbalna sredstva da iskažu svoje ideje - naglašavanja, uzdahe, oklevanja, promene tona; tekstovi pesama ne uključuju samo izjave, poruke i priče, već i molbe, psovke i naredbe“ (Frith, 1988, 120).U ovome svakako ima istine; no, bitno je ipak istaći da drama često uključuje i poeziju (od renesansnih autora poput univerzitetskih umova ili Šekspira, pa do stvaralaca dvadesetog veka, kao što je Eliot, stih je često bio neizostavni deo dramskog teksta), a vrlo često i muziku (kao što je, na primer, Dezdemonina pesma o vrbi u Otelu, a da i ne govorimo o komplikovanijim formama kao što su mjuzikli, sa svojom kombinacijom drame, poezije, pop muzike i pop teksta, te performansa). Osim toga, i dramski se tekstovi, bez obzira na to što je njihov književni element samo jedan deo značenja, već vekovima, uz manje ili veće zanemarivanje teatrološkog aspekta, tumače prosto kao pisana književnost, tako da se sličan pristup može primeniti i kada su pop tekstovi u pitanju. To, naravno, ne znači da muzički element u potpunosti treba zanemariti - ponekad je on neophodan za razumevanje samog koncepta neke pesme („Boemska raspodija“, na primer, jedna je od težih pesama za tumačenje, ali sve promene koje se u njoj dešavaju - i pesničke i muzičke - lakše je staviti u određeni kontekst kada se ima u vidu činjenica da po svojoj muzičkoj strukturi ova pesma zaista prati formu klasične rapsodije, što onda omogućava - između ostalog - i njeno tumačenje u skladu sa očekivanjima tog žanra). Često, takođe, muzika diktira dužinu nekog stiha, i stoga i odabir reči; te kada pevač namerno odluči da malo promeni izgovor ili dužinu neke reči i ne učini ono što bi se od njega očekivalo na osnovu muzike (kao, na primer, u pesmi "Hey Jude“, gde reč "better" na kraju drugog stiha zauzima mnogo veći muzički prostor nego što bi trebalo), onda to možda nosi i neko značenje, stavlja namerni naglasak na neku ideju, ili pak, u deridovskom smislu, samim odsustvom nečega ukazuje na njegovo prisustvo.

Kada je o samoj književnoj analizi pop tekstova reč, najbolje bi bilo primeniti hermeneutički pristup, s posebim naglaskom na intertekstualnosti. Hermeneutika ima dugu tradiciju u teologiji i filozofiji, i bez obzira na razne druge modele tumačenja koji su se u međuvremenu pojavili, ona ipak opstaje - pogotovo na tlu nauke o književnosti - pa čak, kako navodi Džoel Vajnshajmer (Joel Weinsheimer) u predgovoru Sondijevom (Szondi) Uvodu u književnu hermeneutiku, dobija i novu energiju od takozvanog ,antiteorijskog“ pokreta (vid. Szondi, 1995, xi). Herme- 
neutika polazi od toga da tekst ima neko istinsko značenje, a na kritičaru ostaje da se zapita da li je to značenje istinsko za autora ili za čitaoca. U velikom broju slučajeva, naravno, tumačenje nekog dela mnogo više toga otkriva o samom tumaču nego o autoru, što, svakako, samo govori u prilog univerzalnosti tog dela. Kada je reč o popularnoj muzici, njena je univerzalnost jedan od zahteva pri samom stvaranju - nikada se ne sme izgubiti iz vida sama muzička industrija, odnosno činjenica da autori popularne muzike nastoje da dopru do što većeg broja slušalaca ne bi li prodali što više ploča, a stihovi sa kojima će se saživeti većina publike svakako su jedan od načina da to i ostvare. Kako je još pre više decenija rekao Pol Makartni, iako nam se možda čini da je svetu dosta „besmislenih ljubavnih pesmica“, dovoljno je osvrnuti se oko sebe i videti da to ipak nije istina.

Hermeneutika, dakle, kao umetnost tumačenja - ars interpretandi - u središte analize postavlja sam tekst. Ipak, s obzirom na to da književna analiza ne opstaje u vakuumu - odavno je već postalo jasno koliko su neodržive novokritičke ideje koje insistiraju na tome da je tekst u potpunosti samodovoljan i samoodrživ - pojedini elementi iz života stvaralaca ne smeju se prenebregnuti. To, naravno, ne znači da sve treba tumačiti u svetlu biografskih činjenica, ili pak pronalaziti u stihovima pesama ekvivalente stvarnim događajima (teško da bi ijedan kritičar, ma koliko bio naklonjen biografskom tumačenju, uspeo da u pesmi "Helter Skelter" Bitlsa pronađe pozive na krvoproliće), već pre da te činjenice i te kako utiču na sama dela, koja je, shodno tome, ponekad lakše razumeti ako se stave u odgovarajući biografski kontekst. Tako se, uostalom, tumači i umetnička poezija - Kitsove (Keats) ode se, na primer, mogu tumačiti i samo kao odraz pesnikove preokupacije odnosom stvarnosti i mašte ili kroz intertekst grčke mitologije; no, melanholični ton i snažna tema smrti svakako dobijaju mnogo dublji odjek ako se zna da je većina tih pesama nastala u doba kada je pesnik već znao da mu se bliži kraj. Plovidbe (Voyages) Harta Krejna (Hart Crane) mogu biti prosto orfička promišljanja o izgubljenoj ljubavi, nevinosti i iskustvu, ali pesnikovo očajanje zbog lične romantične nesreće, kao i (gotovo sudbinska) opsednutost morem toj jezičko-lirskoj daju i jednu intimniju nijansu, pa čak i proročki ton, s obzirom na Krejnovu „smrt od vode“ nepunu deceniju po objavljivanju Plovidbi. Ponekad je biografski pristup ne samo teško, već i nemoguće zaobići - Lenonova (John Lennon) „Balada o Džonu i Joko“ ne može se razumeti bez predznanja makar o tome ko su njeni naslovni junaci. Povrh svega, tumačenje je proces, a ne stanje, tako da je značenje veoma fluidna kategorija koja se menja u zavisnosti od samog tumača i od konteksta u kome se tumačenje odvija. Tako, na primer, u februaru 1991, novinar Orindž Kaunti Redžistera, pišući o tada tek objavljenom albumu Innuendo grupe Kvin (Queen), zaključuje da je pesma "The Show Must Go On" melodramatično izmotavanje Fredija Merkjurija, te da je vrlo lako zamisliti pevača kako se šepuri pred ogledalom i uzvikuje da se nikada neće predati; u svetlu Merkjurijeve smrti, međutim, tumačenje se potpuno menja, i nekoliko godina kasnije, u tekstu za časopis Modžo, novinar Dejvid Tomas (David Thomas) u istoj pesmi vidi „hrabrost koja prkosi smrti“ (Thomas, 1999, 75). Može se zaključiti da značenje stvaraju, 
zajedničkim snagama, autor i kontekst u kome pesma nastaje s jedne, i tumač i kontekst $\mathrm{u}$ kome se pesma interpretira s druge strane. To nije neobično, s obzirom na to da ono što je zajedničko i za poeziju i za pop tekst jeste to što, za razliku od običnog govora, pa čak i proze, treba da iskažu neko značenje na relativno malom prostoru, zbog čega pesnici i tekstopisci pribegavaju sažimanju značenja - ideje su zgusnute, koristi se manje reči, značenje se prenosi ne samo onim što je iskazano, već i onim na šta se aludira ili onim što se može pročitati između redova, a sve to rezultira češćom dvosmislenošću krajnjeg teksta; dvosmislenošću koja samom svojom prirodom poziva na tumačenje (vid. Levitin, 2010, 26). Upravo zato što značenje pesme - bilo da je reč o poeziji ili pop tekstu - nije potpuno i jasno definisano, mi, kao čitaoci i slušaoci, postajemo i tumači, čime direktno učestvujemo u procesu stvaranja značenja neke pesme.

Ideja da umetnost ne nastaje u vakuumu objašnjava i zašto je potrebno posebnu pažnju posvetiti intertekstualnosti. Detmar i Riči kažu da popularne pesme mogu imati podjednako zgusnuto značenje i bogatu aluzivnost kao i najbolje imažističke tvorevine - zato što, poput imažističkih pesama, kroz malo reči treba da iskažu mnogo toga. Dalje, oni tvrde da

[n]a izvesnom nivou, to znači da kritičar mora istražiti načine na koje rok stihovi, kao i poezija, aludiraju na druge verbalne tekstove, poput načina na koje rok umetnici prizivaju literarnu muzu u bezbrojnim pop standardima, od Kejt Buš i njenog jezgrovitog sinopsisa Orkanskih visova, preko Bouvijeve grandiozne dramatizacije Orvelove 1984 u pesmi "Diamond Dogs", pa do benda U2 i njihove prepredene upotrebe Šelijevog Alastora u svrhu parodije savremene medijske kulture u koncertnom izvođenju pesme "Mysterious Ways" (Dettmar\&Richey, 1999, 3).

Aluzija na književne tekstove zaista ima mnogo - osim pomenutih primera, mogla bi se navesti i Lenonova česta pozivanja na viktorijanske pesnike nonsensa kao što su Luis Kerol (Lewis Carroll) i Edvard Lir (Edward Lear), pesme inspirisane Tolkinovim svetom benda Led Cepelin (Led Zeppelin) ili Kvinovo direktno citiranje Brauningove (Browning) poezije ili Šekspirovog Makbeta. Česte su, potom, i auto-aluzije, odnosno, autoreferencijalnost, koja se najbolje može uočiti u pesmi Bitlsa "Glass Onion", koja citira stihove iz nekih ranijih pesama, ili se pak ponegde i neposredno nastavlja na njih. Takođe, ono što pop muzici daje još jedan intertekstualni nivo jeste njena sposobnost da citira neki muzički tekst ili na njega aludira - što je ,vrsta intertekstualnosti koja nije na raspolaganju većini drugih umetničkih oblika" (Dettmar \&Richey, 1999, 4). Tako, recimo, pesma "It's a Hard Life“" grupe Kvin počinje direktnim muzičkim citatom već pomenute Leonkavalove arije "Vesti la Giubba“, čime se između ova dva dela odmah uspostavlja značenjski dijalog; dok "United States of Eurasia“" grupe Mjuz (Muse) sadrži deo Šopenovog Nokturna Op. 9. Ovakva dinamika omogućava autorima da svojim delima daju još jednu dimenziju značenja, a slušaocima i kritičarima da u to značenje možda lakše prodru, ili makar da uspeju da delo koje tumače smeste u neki širi kontekst koji je možda i najbolje opisati služeći se Eliotovim terminima tradicije i indivi- 
dualnog talenta, gde umetnost može istinski da napreduje jedino ako njeni autori dobro poznaju dotadašnju baštinu i potom joj dodaju i vlastiti doprinos. U svakom slučaju, značenje u velikoj meri zavisi od asocijacija koje autori upliću u svoje delo, a slušaoci-čitaoci-tumači otkrivaju i rasvetljuju.

Tekstovi popularnih pesama se, dakle, s punim pravom mogu smatrati oblikom poezije, te tumačiti na isti način na koji se tumači i poezija. Ovakav pristup, koji na postmodernistički način zanemaruje zastarele podele na pravu i trivijalnu umetnost, pokazuje, pa i dokazuje, da popularne pesme mogu da stoje rame uz rame sa drugim vrstama poezije. A ako se umetničko vrednovanje ipak i zanemari, može se svejedno sa sigurnošću tvrditi da, kako je to Makartni rekao, svetu nikada neće dosaditi „besmislene ljubavne pesmice“, zato što se i u njima krije sve ono što odlikuje pravu umetnost - emocije, ideje, igra.

\section{LITERATURA}

Anon. (1 Feb 1991). "Queen Aims to Reclaim its Throne“. The Orange County Register. Preuzeto sa: http:/queenarchives.com/index.php?title=Queen - 02-01-1991 _ Innuendo The Orange County Register

Barr, J. (18 Sept 2006). ”Is it Poetry or is it Verse?" Poetry Foundation. Preuzeto sa: www. poetryfoundation.org/article/178645

Core, P. (1984). Camp: The Lie that Tells the Truth. New York: Delilah Books.

Dettmar, K. J. H. \& Richey,W. (eds). (1999). Reading Rock and Roll: Authenticity, Appropriation, Aesthetics. New York: Columbia University Press.

Dona, M. (2008). Filozofija muzike (s italijanskog prevela Alenka Zdešar-Ćirilović). Beograd: Geopoetika.

Eckstein, L. (2010). Reading Song Lyrics. Amsterdam \& New York: Rodopi.

Frith, S. (1988). Music for Pleasure: Essays in the Sociology of Pop. New York: Routledge.

Frith, S. \& Goodwin A. (eds.). (1990). On Record: Rock, Pop, and the Written Word. London $\&$ New York: Routledge.

Gracyk, T. (2007). Listening to Popular Music - Or, How I Learned to Stop Worrying and Love Led Zeppelin. Ann Arbor: The University of Michigan Press.

Holt, F. (2007). Genre in Popular Music. Chicago \& London: The University of Chicago Press.

Keightley, K. "Reconsidering Rock." (2001). U: Frith, Simon, Straw, Will \&Street, John (eds.). (2001). The Cambridge Companion to Pop and Rock. (pp. 109-142) Cambridge: Cambridge University Press.

Levitin, D. (2010). The World in Six Songs: How the Musical Brain Created Human Nature. London: Aurum Press Ltd.

Luebke, S. R. (1995). “In Defense of Popular Music.” Preuzetosa: files.eric.ed.gov/fulltext/ ED382965.pdf

McRobbie, A. (1995). Postmodernism and Popular Culture. London \& New York: Routledge.

Middleton, R. (2001). "Pop, Rock and Interpretation.” U: Frith, Simon, Straw, Will \& Street, John (eds.). (2001). The Cambridge Companion to Pop and Rock. (pp. 213-225) Cambridge: Cambridge University Press.

Moore, A. F. (ed.). (2003). Analyzing Popular Music. Cambridge: Cambridge University Press. Music and Lyrics. (2007). Dir. Marc Lawrence. Perf. Hugh Grant, Drew Barrymore. Warner Bros. 
Nabokov, V. (1988). Lolita. (s engleskog preveo Branko Vučićević). Beograd: Narodna knjiga-Bigz. Pullman, P. (2005). "Introduction". U: Milton, John. (2005) Paradise Lost. (pp. 1-10) Oxford: Oxford University Press.

Shuker, R. (2001). Understanding Popular Music (2 $2^{\text {nd }}$ edition). London \& New York: Routledge. Steinholt, Y. B. (s.a.). "Cognitive Poetics in the Analysis of Popular Music: A New Approach to Song Lyrics?" Preuzeto s: www.hum.uit.no/a/steinholt/cog_poe.pdf

Szondi, P. (1995). Introduction to Literary Hermeneutics (transl. by Martha Woodmansee). Cambridge: Cambridge University Press.

Thomas, D. (Aug. 1999). “Their Britannic Majestic Request”. Mojo, pp. 72-89.

Will, T. (2003). Studying Popular Music Culture. London: Arnold.

Bojana Vujin

\title{
SILLY LOVE SONGS: HOW TO APPROACH POP AND ROCK POETRY
}

\begin{abstract}
SUMMARY
Criticism of popular music often does not take into account the fact that a song's lyrics might have equal value to its melodic component, focusing instead on music only, or considering the lyrics a necessary, but essentially banal, part of the song's meaning. This paper tries to rectify that fact, by focusing on the similarities and differences between traditional, written poetry and its popular form, pop and rock lyrics. The paper analyses the elementswhich constitute a poem's (or a song's) meaning and sound, such as its visual representation, its formal and metric features, figures of speech that focus on the aural dimension, or pronunciation of certain words. While similarities with dramatic works are also mentioned, the conclusion still remains that poetry is the form closest to pop and rock lyrics. Therefore, approaches that are traditionally used when analysing written poetry, such as hermeneutic or intertextual, can undouubtedly be also used in the analysis of its popular counterpart, pop and rock lyrics.

Key words: poetry, popular music, hermeneutics, intertextuality, lyrics
\end{abstract}

